\title{
NORMA PEDAGOGIS DAN ANALISIS KEBUTUHAN BELAJAR DALAM PEMBELAJARAN BAHASA INDONESIA UNTUK PENUTUR ASING (BIPA)
}

\author{
oleh Imam Suyitno \\ FS Universitas Negeri Malang
}

\begin{abstract}
The teaching-learning process of Indonesian involving foreigners as the learners differs in characteristics from the teaching-learning process of Indonesian in general. The differences are due to the learners' cultural backgrounds. An analysis of their learning needs and pedagogical norms of language learning is required in the selection of the materials and strategies for the teaching-learning process of Indonesian involving them as the learners. Results of analysis on their entry level, learning style, and learning objective will direct the teachers in selecting the language teaching materials and strategies. In addition, the materials and strategies are also influenced by the teachers' own pedagogical norms.
\end{abstract}

Keywords: needs analysis, pedagogical norms, teaching materials, teaching strategies

\section{A. PENDAhuluan}

Pembelajaran BIPA memiliki peranan penting dalam kaitannya dengan posisi Indonesia yang akhir-akhir ini menjadi salah satu sasaran kunjungan orang-orang asing. Dengan dibukanya pasar kerja di Indonesia, hal ini memperbesar peluang bagi orang asing untuk memasuki berbagai lapangan kerja di Indonesia. Mereka berupaya mempelajari bahasa Indonesia agar dapat berkomunikasi lebih baik dengan pejabat, sejawat, karyawan, ataupun masyarakat umum di Indonesia (Sammeng, 1995). Kenyataan ini menjadi tantangan bagi penyelenggara BIPA yang menuntut pemikiran dan penanganan secara sungguh-sungguh pelaksanaan program pembelajaran BIPA.

Dalam upaya penanganan program BIPA, perlu dipikirkan secara sungguhsungguh tentang norma pedagogis yang akan digunakan sebagai panduan dalam pembelajaran (Magnan, 202). Norma pedagogis ini akan mengarahkan pada pemilihan dan penpengajartan materi ajar untuk kepentingan pembelajaran BIPA. Prinsipprinsip pemilihan tersebut menjadi hal yang penting bagi pengajar BIPA dan pengembang materi dalam upaya menggabungkan aspekaspek bahasa ke dalam program pembelajaran dan menyampaikannya kepada pelajar. Norma pedagogis tersebut melibatkan kajian terhadap norma penggunaan bahasa yang aktual dan implementasinya pada tujuan pedagogis, yakni mulai dari perancangan materi buku teks sampai pada penciptaan aktivitas kelas seharihari (periksa Bardovi-Harlig dan Gass, 2002).

Penentuan norma pedagogis pembelajaran BIPA tidak dapat dilepaskan dari analisis kebutuhan belajar pelajar BIPA. Bila dilihat dari kondisi pelajarnya, pembelajaran BIPA di Indonesia memiliki karakteristik yang berbeda dengan pembelajaran bahasa Indonesia pada umumnya. Pelajar BIPA adalah pelajar asing yang memiliki latar belakang budaya yang berbeda dengan budaya bahasa yang dipelajarinya. Selain itu, kebanyakan pelajar BIPA di Indonesia adalah pelajar dewasa. Sesuai dengan kenyataan tersebut, bahwa perbedaan terpenting antara pembelajaran BIPA dengan pembelajaran bahasa Indonesia pada umumnya adalah (1) BIPA tidak mengintegrasikan pelajar ke dalam 
lingkungannya, (2) BIPA hampir dipelajari pada usia dewasa atau pada ketika seseorang telah menguasai sejumlah struktur dari bahasa pertamanya, dan (3) BIPA diolah di luar sistemnya sendiri.

Dalam kaitannya dengan pembelajaran BIPA, ada beberapa sifat yang harus diperhatikan. Pertama, pelajar BIPA sudah memiliki cukup banyak pengetahuan dan wawasan, sehingga kebutuhan mereka juga kebutuhan orang dewasa bukan lagi kebutuhan anak-anak. Yang kedua, bahwa orang asing (orang Barat) suka mengekpresikan diri, mempresentasikan sesuatu, mengemukakan pendapat, sehingga tugas di luar kelas akan sangat menarik. Terakhir, untuk mengakomodasi minat dan kebutuhan yang mungkin berbeda dari yang satu dengan yang lain perlu disiapkan materi yang bervariasi (periksa Soegino, 1995:6).

Bertolak dari uraian di atas, dalam upaya memahami norma pedagogis yang sejalan dengan kebutuhan belajar pelajar asing, dalam uraian berikut ini, disajikan pembahasan tentang (a) kondisi awal pelajar BIPA, (b) norma pedagogis pemilihan materi pembelajaran BIPA, (c) pendekatan pembelajaran BIPA, dan (d) teknik pembelajaran BIPA.

\section{B. KONDISI AWAL PELAJAR BIPA}

Pelajar BIPA adalah pelajar asing yang berasal dari berbagai negara. Karena itu, mereka memiliki latar belakang bahasa dan budaya yang berbeda dengan bahasa dan budaya Indonesia. Selain itu, mereka juga memiliki latar belakang pengetahuan dan keterampilan berbahasa Indonesia yang bervariasi. Bahkan, gaya dan strategi belajarnya pun sangat bervariasi dan sangat bergantung pada budaya mereka masingmasing.

Dalam pembelajaran BIPA, perbedaan bahasa dan budaya pelajar asing memiliki konsekuensi pada pemilihan materi bahasa Indonesia yang akan diajarkan. Hal ini disebabkan pemerolehan bahasa kedua dipengaruhi secara kuat oleh bahasa pertama.
Satu-satunya penyebab kesulitan dan kesalahan dalam belajar bahasa kedua atau bahasa asing adalah pengaruh bahasa pertama pelajar. Dari pendapat di atas, dapat dikatakan bahwa pemerolehan bahasa kedua ditandai oleh adanya interferensi dari bahasa pertama. Interferensi ini lambat laun akan berkurang, yang akhirnya pelajar mencapai penguasaan bahasa kedua mirip dengan penutur asli.

Pelajar BIPA memiliki tingkat kemampuan yang berbeda-beda, mulai pelajar yang tingkat pemula sampai dengan pelajar tingkat lanjut. Perbedaan tersebut berimplikasi pada pemilihan materi ajar BIPA yang lebih bervariasi. Keberagaman materi tersebut dimaksudkan untuk mempermudah dan memperlancar pelajar BIPA dalam menguasai materi ajar BIPA. Kebutuhan materi BIPA sebagaimana dikemukakan dalam kondisi di atas mengundang para penulis buku untuk mengembangkan materi ajar BIPA. Sudiroatmadja (1993) mencatat ada beberapa penulis buku, baik penulis asing maupun penulis Indonesia yang menulis bahasa Indonesia untuk orang asing. Satu tujuan yang hendak mereka capai ialah mempermudah pelajar menguasai bahasa Indonesia.

Pelajar BIPA pada umumnya adalah pelajar dewasa. Sejalan dengan kedewasaan pelajar asing tersebut, ada beberapa hal yang harus diperhatikan dalam pemilihan materi BIPA. Yang pertama, orang dewasa sudah memiliki cukup banyak pengetahuan dan wawasan, sehingga kebutuhan mereka juga kebutuhan orang dewasa bukan lagi kebutuhan anak-anak. Oleh karena itu, topik-topik aktual yang ingin mereka pelajari adalah topik umum seperti masalah lingkungan, hubungan antarmanusia, energi, peristiwa dunia, dan sebagainya. Yang kedua, orang asing (orang Barat) suka mengekpresikan diri mereka, mempresentasikan sesuatu, mengemukakan pendapat, sehingga tugas di luar kelas atau membuat proyek kecil-kecilan akan sangat menarik. Terakhir, untuk mengakomodasi minat dan kebutuhan yang mungkin berbeda dari yang satu dengan yang lain, diperlukan kesiapan materi yang bervariasi. 
Tujuan pelajar asing belajar BIPA adalah untuk memperlancar berbahasa Indonesia dan mengenal budaya Indonesia dari dekat. Kelancaran berbahasa Indonesia tersebut diperlukan oleh mereka karena (a) mereka mengambil program tentang Indonesia di universitas asalnya, (b) mereka akan melakukan penelitian di Indonesia, (c) mereka akan bekerja di Indonesia, (d) mereka akan meneliti masalah bahasa Indonesia, dan (e) mereka akan tinggal di Indonesia dalam waktu lama. Gambaran tentang tujuan belajar BIPA tersebut berimplikasi pada penyiapan materi belajar yang sesuai dengan tujuan tersebut. Dengan demikian, materi pembelajaran BIPA ini memiliki kaitan yang erat dengan masalah pemenuhan kebutuhan pelajar asing.

Hal di atas sejalan dengan pendapat Mackey dan Mountford (dalam Sofyan, 1983) yang menjelaskan bahwa ada 3 kebutuhan yang mendorong seseorang belajar bahasa, yakni (1) kebutuhan akan pekerjaan, (2) kebutuhan program latihan kejuruan, dan (3) kebutuhan untuk belajar. Temuan tersebut juga sejalan dengan pendapat Hoed (1995) yang menyatakan bahwa program BIPA bertujuan untuk (1) mengikuti kuliah di perpengajaran tinggi Indonesia, (2) membaca buku dan surat kabar guna keperluan penelitian, dan (3) berkomunikasi secara lisan dalam kehidupan sehari-hari di Indonesia. Ketiga tujuan itu masing-masing masih dapat dipecah lagi menjadi beberapa tujuan khusus, misalnya, untuk mengikuti kuliah di perpengajaran tinggi di Indonesia memerlukan pengetahuan bahasa Indonesia sesuai dengan bidang ilmu yang diikuti (ilmu sosial, ilmu teknik, ekonomi, dan sebagainya). Begitu pula, untuk keperluan penelitian tergantung dari bidang apa yang akan diteliti. Untuk belajar bahasa Indonesia lisan guna keperluan komunikasi dengan penduduk diperlukan pula pengkhususan, misalnya komunikasi formal atau informal. Berdasarkan kebutuhan-kebutuhan dan tujuan pembelajaran tersebut, materi BIPA dipilih dan disusun untuk pemenuhan kebutuhan atau pencapaian tujuan itu.

\section{NORMA PEDAGOGIS DALAM PEMILIHAN MATERI AJAR BIPA}

Norma pedagogis pembelajaran bahasa secara signifikan mengarahkan pengajar dalam pemilihan materi bahasa yang akan diajarkan. Norma pedagogis belajar bahasa yang mengarah pada pengajaran tatabahasa, dalam pemilihan materi ajar diutamakan pada penonjolan kaidah, yakni pengurangan variasi bahasa melalui pemilihan fitur-fitur bahasa yang paling umum dan netral. Atas dasar norma tersebut, pengajaran bahasa menggunakan metode auidio-lingual. Materi ajar bahasa yang dipilih adalah fitur bahasa yang (a) memiliki frekuensi penggunaan dan keberterimaan yang tinggi, (b) digunakan secara luas, (c) tidak terlalu kompleks untuk dipelajari, dan secara bertahap berubah ke arah fitur yang jarang digunakan, lebih sempit penggunaannya, dan lebih kompleks variannya (Valdan dalam Magnan dan Walz, 2002).

Lebih lanjut, pembelajaran bahasa dipengaruhi oleh prinsip-prinsip interaksi sosiolinguistik. Prinsip ini mengarahkan pada pembelajaran bahasa secara komunikatif. Norma pedagogis ini menyarankan pemilihan dan penataan urutan fitur linguistik yang diprioritaskan pada fitur instruksi. Data bahasa yang digunakan sebagai bahan ajar adalah data ujaran penutur asli dalam berbagai konteks sosial dan dari pelajar bahasa. Prioritas pada koreksi kesalahan masih menjadi kriteria yang dipertentangkan. Dalam kaitannya dengan koreksi kesalahan, pengajar perlu mempertimbangkan (a) pengaruh kesalahan pada keterpahaman pesan, (b) tingkat kesalahan tersebut jika diukur dari tingkat kesalahan yang dialami penutur asli, dan (c) hubungan antara kesalahan dan keadaan sistem pelajar.

Atas dasar kajiannya pada aspek-aspek sosiolinguistik dan psikolinguistik dari ragam bahasa, Valdan menyarankan bahwa materi bahasa yang dipilih sebagai materi ajar seharusnya (a) mencerminkan ujaran aktual penutur bahasa target dalam situasi komunikatif yang otentik, (b) sesuai dengan penggunaan bahasa yang diidealkan oleh penutur asli, (c) sesuai dengan harapan penutur asli dan pelajar 
asing yang berkeenaan dengan tipe perilaku bahasa yang sesuai untuk pelajar asing, dan (d) memperhitungkan faktor proses dan pembelajaran. Lebih lanjut, Valdan memperluas kajiannya pada fokus variasi sosiopragmatik dan sosiostilistik. Untuk itu, norma pedagogik pengajaran bahasa menekankan pada makna, fungsi, dan konteks.

Sejalan dengan norma pedagogis yang di uraikan di atas, materi bahasa yang dikembangkan dalam pembelajaran BIPA didasarkan pada tingkat kemampuan bahasa Indonesia pembelajarnya. Untuk tingkat pemula diberikan materi bahasa di antaranya adalah kata sapaan, ungkapan keseharian sederhana, kalimat sederhana, kalimat aktif, kalimat pasif, kalimat negatif, preposisi, kata/kalimat tanya, kata bilangan, dan afiksasi $(\mathrm{me}(\mathrm{N})-$, me(N)-kan, me(N)-i, se-nya, di-, dikan, di-i, ber-, ter-, dan pe(N)-). Untuk tingkat tingkat menengah diberikan materi bahasa di antaranya adalah ungkapan dalam bahasa Indonesia, kalimat kompleks, kalimat aktif, kalimat pasif, kalimat negatif, kalimat transitif dan intransitif, preposisi, kalimat tanya, dan afiksasi (me(N)-, me(N)-kan, me(N)-i, se-nya, di-, di-kan, di-i, ber-, ter-, dan pe(N)-, pe(N)-an, per-an, ber-an, memper-kan, member-kan,). Adapun untuk tingkat lanjut, materi yang disajikan pada pokoknya hampir sama dengan materi untuk tingkat menengah, hanya saja dari tingkat kekompleksannya yang berbeda.

Untuk tingkat lanjut, penekanannya lebih pada pemahaman secara analitis terhadap materi bahasa. Kepada pelajar, selain diberikan materi-materi tersebut, banyak juga diberikan materi-materi analisis, yakni menganalisis kalimat salah dan membenarkannya serta mengubah pola kalimat tanpa mengubah maknanya. Materi menyimak dan wicara dikembangkan dengan menggunakan materi dialog, mulai dari dialog yang sangat sederhana (misalnya: salam) sampai dengan dialog yang sangat kompleks dan formal (misalnya: seminar). Materi dialog ini dalam praktek pembelajarannya sekaligus dimanfaatkan untuk materi pembelajaran menyimak. Dengan demikian materi pembelajaran menyimak dan wicara dikemas dalam satu wujud materi.
Selain materi yang berbentuk dialog, dalam pembelajaran menyimak, juga memanfaatkan wacana yang ada dalam kegiatan berbahasa sehari-hari, misalnya menyimak berita atau percakapan yang ada di televisi, radio, maupun percakapan sehari-hari. Materi-materi tersebut disajikan kepada pelajar sesuai dengan tingkat kemampuannya. Untuk tingkat pemula, disajikan materi-materi dialog keseharian sederhana dalam bahasa Indonesia. Untuk tingkat menengah diberikan materi dialog keseharian yang agak kompleks dan dialog-dialog formal yang sederhana. Adapun untuk tingkat lanjut diberikan materi-materi dialog yang lebih kompleks baik berkaitan dengan topik keseharian maupun topik formal.

Pengembangan materi membaca dan menulis disesuaikan dengan tingkat kemampuan pelajarnya. Untuk tingkat pemula diberikan bacaan dalam bahasa Indonesia yang sederhana, untuk tingkat menengah diberikan bacaan dalam bahasa Indonesia yang agak kompleks, dan untuk tingkat lanjut diberikan bacaan bahasa Indonesia yang kompleks. Meteri-materi bacaan sederhana banyak diambilkan dari bacaan yang ada di majalah anak-anak, bacaan yang ada pada buku bahasa Indonesia di sekolah dasar, atau bacaan yang disusun sendiri oleh pengajar. Adapun bacaan untuk tingkat mengah dan tingkat lanjut dapat menggunakan bacaan yang ada di surat kabar atau pun majalah. Adapun untuk materi menulis dimulai dari menulis kalimat, menulis topik sederhana tentang pengalamannya atau apa yang telah dilakukkannya sampai dengan menulis makalah untuk diseminarkan dalam seminar di kelasnya.

Pengembangan materi budaya diarahkan pada pembekalan budaya pada pelajar asing untuk kehidupannya sehari-hari di masyarakat. Pokok-pokok materi yang perlu diberikan pada pelajar adalah tentang bagaimana hidup dalam keluarga, berteman, bermasyarakat, dan sopan-santun dalam pergaulan. Yang prinsip dalam pemberian materi budaya ini adalah membekali pelajar BIPA agar mampu berbahasa Indonesia sesuai dengan situasi dan kondisinya. 
Dalam pembelajaran bahasa asing, budaya dapat diajarkan melalui karya sastra karena karya sastra merupakan hasil pemikiran penulis yang merupakan hasil kontak diri penulis, baik disadari maupun tidak, dengan realitas sosial dan pola budaya. Akan tetapi, yang menjadi masalah adalah cara menentukan karya sastra yang mencerminkan pola dan indikator budaya yang ingin diajarkan kepada pembelajar bahasa asing. Karya sastra memang bisa digunakan untuk mengajarkan budaya ideosinkratik lokal yang berperan dalam membentuk budaya universal. Karena itu, yang diajarkan kepada pembelajar bahasa seharusnya bukan hanya budaya universal akan tetapi juga perlu diperhatikan budaya lokal (periksa Seelye, 1994).

Salah satu alternatif untuk mengajarkan bahasa melalui analisis karya sastra bagi guru yang ingin mendapatkan pemahaman antropologis tentang budaya tetapi tidak memiliki latar belakang orientasi empiris tentang ilmu sosial adalah melalui folklor. Menurut Taylor, folklor adalah materi yang mewariskan tradisi, baik melalui kata-kata maupun adat dan kebiasaan yang bisa berupa nyanyian rakyat, cerita rakyat, peribahasa, atau materi lain yang disajikan melalui kata-kata.. Folklor juga bisa berupa alat-alat tradisional dan objek-objek fisik seperti pagar dan tali, ornamen tradisional, simbol-simbol tradisional seperti swastika.

Pengembangan dan penataan materi perlu disesuaikan dengan kebutuhan dan tingkat kemampuan pelajarnya. Karena itu, pengelolaan materi pembelajaran BIPA perlu memperhatikan tiga hal, yakni (1) orientasi materi hendaknya diarahkan dan dititikberatkan pada materi-materi yang (a) dapat dipakai dan berpotensi untuk dilatihkan, (b) benar-benar ada dan dipakai dalam komunikasi nyata di masyarakat, dan (c) mampu mengembangkan kompetensi untuk berlatih dan memahami pola serta mampu mengembangkan pemahaman bahasa Indonesia melalui bentuk-bentuk percakapan/ dialog yang situasional-kontekstual; (2) rentangan dan penataan materi diupayakan pada materi yang mengacu pada aspek-aspek yang menentukan bagaimana bahasa Indonesia digunakan, yakni aspek-aspek: (a) kosa kata, (b) pola kalimat, (c) wacana/percakapan, (d) lafal/ucapan dan intonasi, dan (e) pengolahan ide; dan (3) materi-materi pembelajaran perlu ditata berdasarkan unit-unit satuan ujaran yang komunikatif secara terpadu (periksa Suyitno, 2005).

\section{PENDEKATAN PEMBELAJARAN BIPA}

Pendekatan yang digunakan dalam pembelajaran BIPA dititikberatkan pada penggunaan bahasa daripada penjelasan tatabahasa. Pengajar dalam pembelajaran lebih banyak memfungsikan dirinya sebagai mitra bicara bagi siswanya. Dalam hal ini, pengajar memberikan latihan pemakaian bahasa untuk berkomunikasi. Untuk itu, materi pembelajaran diwujudkan dalam bentuk keterampilan berbahasa.

Dalam pembelajaran BIPA, bahasa Indonesia ditempatkan sebagai alat komunikasi, bukan sebagai materi bahasa yang dihafalkan atau dianalisis. Bahasa Indonesia difungsikan sebagai alat komunikasi baik secara lisan maupun tulis. Karena itu, dalam pembelajaran BIPA, tujuan yang ingin dicapai adalah kemampuan pelajar untuk berkomunikasi dengan menggunakan bahasa Indonesia yang dipelajarinya. Dengan demikian, pelajar diharapkan dapat memiliki kemampuan komunikatif(Seelye, 1994).

Sejalan dengan harapan tersebut, dalam pembelajaran BIPA, ditekankan kepada pelajar BIPA tentang (1) pengetahuan tentang bentuk bahasa yang mungkin dikatakan, (2) pengetahuan tentang kata yang dapat dituturkan dan dapat dipahami oleh pendengar, (3) pengetahuan tentang kata yang sesuai dan wajar menurut konteksnya, dan (4) pengetahuan tentang kata yang pernah diujarkan orang. Dengan penguasaan keempat hal tersebut, seseorang akan dapat berbahasa secara berterima.

Berdasarkan pada perolehan hasil belajar yang ditargetkan, dalam pengajaran 
BIPA, ancangan yang dipilih adalah acangan komunikatif. Seperti halnya ancanganancangan lain, ancangan komunikatif memiliki asumsi tentang hakikat bahasa dan belajar bahasa. Asumsi ancangan komunikatif tentang hakikat bahasa adalah (1) bahasa merupakan sistem dalam pengungkapan makna, (2) bahasa adalah alat bagi manusia untuk berkomunikasi dan berinteraksi, (3) struktur bahasa mencerminkan fungsi penggunaannya dan fungsi komunikatifnya, dan (4) unit utama bahasa bukan hanya berupa unit gramatikal melainkan juga fungsi dan makna komunikasi. Dalam kaitannya dengan belajar bahasa ancangan komunikatif mengajukan tiga prinsip, yakni (1) belajar bahasa terjadi apabila kegiatan itu berlangsung dalam suatu komunikasi yang nyata, (2) dalam kegiatan komunikasi seperti ini, bahasa nyata-nyata digunakan, dan (3) penggunaan bahasa yang nyata inilah yang bagi pelajar bermakna atau fungsional.

Dalam kaitannya dengan ancangan komunikatif, Van Eck (dalam Machmoed, 1990) menjelaskan bahwa pengajaran bahasa dengan ancangan komunikatif memerlukan komponen-komponen berikut ini dalam penentuan tujuan pengajaran bahasa, yakni (1) situasi yang melatarbelakangi penggunaan bahasa, meliputi peranan pembicara, latar, dan pokok bahasan yang dibicarakan; (2) kegiatan kebahasaan apa yang kelak perlu dilaksanakan oleh pelajar; (3) fungsi bahasa yang akan dilaksanakan pelajar dalam penggunaan bahasanya kelak; (4) apa yang dapat dilaksanakan pelajar terhadap setiap pokok bahasan; (5) nosi umum apa yang akan dapat ditangani oleh pelajar; (6) konsep khusus apa yang ditangani oleh pelajar kelak; (7) bentuk bahasa apa yang dipakai oleh pelajar; dan (8) tingkat keterampilan yang kelak dapat dimanifestasikan oleh pelajar. Program pengajaran dengan tujuan tersebut memerlukan kegiatan dan proses belajar yang bervariasi, yang dapat membantu pelajar mencapai perangkat tujuan tersebut.

\section{E. TEKNIK PEMBELAJARAN BIPA}

Dalam kaitannya dengan teknik pembelajaran BIPA, ada beberapa hal yang dikaji, yaitu (1) teknik penyampaian materi, (2) teknik menghadapi pelajar, dan (3) teknik penciptaan suasana belajar. Teknik penyampaian materi dibagi dalam 3 tahap, yakni teknik membuka pelajaran, teknik menyampaian materi baru, dan teknik menutup pelajaran.

Ada beberapa teknik yang dilakukan pengajar dalam memulai pelajaran di kelas, di antaranya adalah (1) memberi salam (greetings), (2) menanyakan keadaan/situasi di tempat tinggal, (3) menanyakan perasaannya, (4) menanyakan kegiatan yang telah dilakukannya, (5) menanyakan tentang waktu (tidur, mimpi, bangun, berangkat sekolah, dsb.), (6) bercerita apa yang telah dilakukan (pengajar), (7) bertanya dengan menggunakan kata-kata atau kalimat yang telah diberikan hari sebelumnya, (8) menanyakan sesuatu yang dibawa atau yang ada pada pelajar, (9) merespon pernyataan/pertanyaan yang sejak awal disampaikan pelajar, (10) menjelaskan hal-hal apa yang akan dilakukan hari itu atau selanjutnya (periksa Suyitno, 2004: 36).

Teknik-teknik tersebut banyak digunakan pengajar dalam memulai pelajaran di kelas. Teknik tersebut bertujuan untuk menciptakan suasana yang akrab dan hangat sebelum memulai pelajaran. Selain itu, teknik semacam ini dapat dimanfaatkan untuk melatih pelajar berani berkomunikasi dengan menggunakan bahasa Indonesia yang dipelajarinya. Dengan demikian, pengajar dapat mengetahui seberapa banyak kata yang telah dikuasai oleh pelajar, pada masalah apa dia mengalami kesulitan, hal-hal apa yang perlu diulangi. Keuntungan lain yang dapat diperoleh dari teknik memulai pelajaran dengan cara seperti ini adalah pengajar dapat memberikan tambahan kata-kata yang sesuai dengan kebutuhan pelajar saat itu, dan kata-kata yang demikian inilah yang sebenarnya fungsional bagi pelajar sebab (1) belajar bahasa terjadi apabila kegiatan itu berlangsung dalam suatu komunikasi yang nyata, (2) dalam kegiatan 
komunikasi seperti ini, bahasa nyata-nyata digunakan, dan (3) penggunaan bahasa yang nyata inilah yang bagi pelajar bermakna atau fungsional.

Teknik yang digunakan oleh pengajar dalam menyajikan materi pada dasarkan menggunakan teknik celup total. Pengajar berusaha sedapat mungkin tidak menggunakan bahasa Inggris. Berbagai cara yang digunakan untuk penyajian materi tersebut diantaranya adalah cara tanya jawab, pelatihan, penugasan, demonstrasi, pemberian konsultasi baik kelompok maupun individual, tutorial, penubian (drill), dan koreksi. Cara yang demikian ini dalam penyajian materi baru dilakukan dalam kegiatan sebagai berikut.

1) Materi yang berupa dialog: (a) pengajar membacakan dialog kemudian pelajar menirukan (cara ini terutama untuk tingkat pemula, untuk tingkat menengah dan tingkat lanjut pengajar tidak perlu memberi contoh), (b) pengajar menunjuk beberapa pelajar untuk membaca teks dialog tersebut, (c) pengajar melatihkan pelafalan kata-kata secara tepat, (d) pengajar menugasi pelajar secara berpasangan memerankan apa yang ada dalam teks dialog, (e) pengajar meminta pelajar menutup buku kemudian merespon pertanyaan/pernyataan pengajar yang diambil dari teks dialog, (f) pengajar menugasi pelajar melakukan dialog dengan menggunakan kata-kata bebas sesuai dengan topik yang ada dalam teks dialog yang baru dipelajarinya, (g) pengajar memberikan kesempatan pada pelajar menanyakan kata-kata sulit yang ada dalam teks dialog, (h) pengajar meminta pelajar membuat kalimat dengan kata-kata baru yang ada dalam dialog, dan (i) pengajar menugasi siswa mengerjakan latihanlatihan baik secara lisan.

2) Materi yang berupa bacaan: (a) pengajar menyampaikan penjelasan awal tentang isi bacaan (pre-reading), (b) pengajar bertanya-jawab dengan pelajar tentang halhal yang ada dalam bacaan, (c) pengajar menyuruh pelajar membaca bacaan per paragraf, dan mengecek pemahamannya tentang isinya, (d) pengajar menanyakan apakah ada kata-kata sulit; dan (e) pengajar menugasi pelajar untuk mengerjakan latihan-latihan dan pertanyaan-pertanyaan tentang isi bacaan.

3) Materi yang berupa tatabahasa: materi yang berupa tatabahasa disajikan dalam bentuk latihan-latihan. Oleh karena itu, pelajar langsung diminta mengerjakan latihanlatihan tatabahasa. Jika ada kesulitan yang dihadapi oleh pelajar, pengajar baru menjelaskannya. Penjelasan yang disampaikan oleh pengajar bukan penjelasan dari segi ilmu bahasa, tapi penjelasan tentang bagaimana seharusnya kata digunakan dalam berbahasa.

Dalam pelaksanaan teknik celup ini, pengajar berusaha semaksimal mungkin untuk tidak menggunakan bahasa Inggris kepada pelajar. Demikian juga pelajar, dianjurkan untuk selalu menggunakan bahasa Indonesia. Jika mereka sekali diberi kesempatan untuk berbahasa Inggris, maka mereka akan selalu meminta penjelasan dalam bahasa Inggris. Hal ini sesuai dengan saran Wolff, dkk. (1988) yang menyarankan bahwa bahwa pengajar BIPA perlu memperhatikan teknik berikut dalam mengajarkan BIPA, yakni (1) berbicaralah kepada pelajar dengan bahasa Indonesia, (2) pakailah kata-kata, bentukan-bentukan, kalimat-kalimat dan tata bahasa yang sudah diketahui pelajar, (3) janganlah memberikan peluang dan keleluasaan kepada pembelajar untuk berbahasa Inggris, sekalipun mereka belum bisa menyampaikan maksudnya dengan bahasa Indonesia yang baik, (4) berbicaralah secara wajar, (5) bila pelajar mengucapkan kalimat yang salah katakanlah kalimat yang dimaksudkan dengan betul, kemudian suruhlah mereka mengulanginya, (6) kesalahan yang dilakukan oleh pelajar hendaklah disikapi sebagai kesalahan bersama, (7) penjelasan tentang kata-kata atau istilah-istilah hendaknya didasarkan pada aspek sosiosemantis dengan mengefektifkan penggunaan contoh-contoh, dan (8) apabila pelajar menemui kesulitan dalam pelatihan (ucapan dan penangkapan) 
kalimat-kalimat panjang, potong- potonglah kalimat tersebut dalam satuan-satuan bermakna mulai dari ujung kalimat.

Teknik penyajian materi tidak saja dilakukan di dalam kelas, tapi juga dilakukan di luar kelas. Teknik yang ditempuh dalam penyajian materi melalui kegiatan di luar kelas ini di antaranya melalui kegiatan tugas luar (ke bank, ke studio foto, ke pasar), bertamu, wawancara dengan mahasiswa Indonesia, kunjungan ke tempat-tempat wisata, melihat benda-benda kerajinan (wayang, keramik, topeng), melihat pertunjukkan, menyaksikan upacara adat (pernikahan, kemati-an), dan sebagainya. Cara yang demikian ini sesuai dengan pendapat bahwa kiat-kiat yang dapat dilakukan dalam pengajaran BIPA, yakni (1) kiat kuliah, (2) kiat penjelasan dengan contoh benda budaya, (3) kiat demonstrasi dan partisipasi aktif, (4) kiat peninjauan ke lapangan atau ekskursi, (5) kiat majalah dinding, (6) kiat tari dan nyanyi, (7) kiat permainan simulasi, (8) kiat informan penutur asli, (9) kiat video-tape, (10) kiat audio-motor units, (11) kiat identifi-kasi secara kultural perilaku umum, (12) kiat identifikasi konotasi kultural, (13) kiat minimalisasi persepsi yang ber-sifat stereotif, dan (14) kiat memanfaatkan bacaan otentik.

Selain teknik penyajian materi, teknik menghadapi pelajar baik di kelas maupun di luar kelas perlu mendapat perhatian dalam pembelajaran BIPA. Hal ini mengingat bahwa pelajar BIPA adalah bukan pelajar Indonesia, yakni pelajar asing yang memiliki latar belakang budaya yang berbeda dengan pengajarnya. Beberapa teknik yang dapat ditempuh dalam menyikapi pelajar BIPA baik di dalam maupun di luar kelas adalah (1) menunjukkan sikap disiplin terhadap waktu, (2) menunjukkan sikap tanggung jawab terhadap kerja/tugas, (3) menunjukkan sikap sebagai teman, (4) menunjukkan sikap yang tahu terhadap masalah bahasa, (5) menunjukkan sikap sabar dan telaten, (6) menunjukkan sikap terbuka, (7) menunjukkan sikap bersemangat.

Dalam pembelajaran bahasa di kelas, suasana kelas sangat menentukan keberhasilan belajar. Suasana kelas perlu diciptakan sekondusif mungkin. Ada beberapa cara yang dapat dilakukan oleh pengajar BIPA dalam menciptakan suasana kelas agar kegiatan belajar-mengajar tetap berlangsung, yakni (1) dengan menggunakan humor, (2) mengubah/ memberikan materi-materi yang menantang, (3) memberikan nyanyian, (4) memberikan teka-teki (puzzles), (5) memberikan kepada pelajar untuk beristirahat sebentar, dan (6) mengajak pelajar pindah ke tempat lain, misalnya(di luar kelas, di warung kopi, dsb. (periksa Suyitno, 2005).

\section{F. PENUTUP}

Pembelajaran BIPA berbeda dengan pembelajaran bahasa Indonesia pada umumnya. Pelajar BIPA adalah pelajar asing yang memiliki bahasa dan budaya yang berbeda dengan pelajar Indonesia. Karena itu, dalam pembelajaran BIPA, diperlukan upaya yang sungguh-sungguh dari para pengajar dan pengelola BIPA.

Keseriusan tersebut hendaknya direalisasikan dalam perencanaan materi ajar, pelaksanaan pembelajaran, atau pun dalam pengelolaan program-program kegiatan pembelajaran lainnnya. Untuk dapat memberikan layanan yang terbaik dalam pembelajaran BIPA, pemahaman tentang norma pedagogik dan analisis kebutuhan belajar pelajar asing asing sangat diperlukan.

\section{DAFTAR PUSTAKA}

Gass, Susan M, dkk. (eds.). 2002. Pedagogical Norms for Second and Foreign Language Learning and Teaching. Philadelphia: John Benjamins Publishing Company.

Hoed, Beny H. 1995. Kerjasama Antarpemerintah dan Antarlembaga untuk Pengembangan BIPA. Makalah Kongres BIPA 1995 Fakultas Sastra Universitas Indonesia Jakarta.

Machmoed, Zaini. 1990. "Proses dan Evaluasi Pembelajaran dan Pengajaran Kompetensi Komunikatif”, dalam 
Warta Scientia, No. 49. Th. XVIII, April 1990.

Magnan, Sally Sieloff dan Walz, Joel. 2002.

"Pedagogical Norms: Development of Concept and Illustrations from French", dalam Gass, Susan M, dkk (eds.). 2002. Pedagogical Norms for Second and Foreign Language Learning and Teaching. Philadelphia: John Benjamins Publishing Company.

Sammeng, Andi Mappi. 1995. Pengajaran Bahasa Indonesia sebagai Bahasa Asing serta Peranannya, Makalah Kongres BIPA 1995 di Fakultas Sastra, Universitas Indonesia Jakarta.

Seelye, H.Ned. 1994. Teaching Culture: Strategies for Intercultural Communication. Illinois: National Textbook Company.

Sudiroatmadja, M.H. 1993. Bahasa Indonesia dalam Masyarakat Dunia. Yogyakarta: Pusat Penelitian Sanata Dharma.
Soegino, S. 1995. Pendekatan KomunikatifIntegratif-Tematis dalam Pengembangan Bahan dan Metodologi Pengajaran BIPA di Indonesia, Makalah Kongres BIPA 1995 Fakultas Sastra Universitas Indonesia Jakarta.

Suyitno, Imam. 2005. Bahasa Indonesia untuk Penutur Asing: Teori, Strategi, dan Aplikasi Pembelajarannya. Yogyakarta: CV Grafika Indah.

Suyitno, Imam. 2004. Pengetahuan Dasar BIPA: Pandangan Teoritis Belajar Bahasa. Yogyakarta: CV Grafika Indah.

Wolff, John U.; Oetomo, Dede; dan Fietkiwicz. 1988. Beginning Indonesian Through Self-Instruction, Book 1. Ithaca: Cornell University, SEAP. 06/01/2008 